\title{
PECULIARITIES OF FORMATION OF STRUCTURE OF WELDED JOINTS IN ARC SURFACING WITH PULSE FEED OF ELECTRODE WIRE
}

\author{
V. A. LEBEDEV ${ }^{1}$, I.V. LENDEL ${ }^{1}$, A.V. YAROVITSYN ${ }^{1}$, E.I. LOS $^{1}$ and S.V. DRAGAN ${ }^{2}$ \\ ${ }^{1}$ E.O. Paton Electric Welding Institute, NASU \\ 11 Kazimir Malevich Str., 03680, Kiev, Ukraine. E-mail: office@paton.kiev.ua \\ ${ }^{2}$ National Shipbuilding University \\ 19 Geroev Staliningrada Ave., 54025, Nikolaev, Ukraine
}

\begin{abstract}
It is shown that process of $\mathrm{CO}_{2}$ arc surfacing with pulse feed of electrode wire in contrast to its continuous feed is characterized by increased stability, lower loss of electrode metal for spattering and improved characteristics of wear resistance of 30KhGSA deposited metal. Determined was an optimum range of parameters of electrode wire pulse feed, namely frequency $10-30 \mathrm{~Hz}$ and relative pulse duration 3-5 units. It is shown that reduction of penetration depth of base metal is achieved due to current decrease at stage of droplet growth in elementary cycle of electrode metal transfer. Comparative examination of microstructure of deposited metal and HAZ was carried out employing scanning electron microscopy at continuous and pulse feed of electrode wire at $\times(500-2000)$ magnifications. 18 Ref., 2 Tables, 10 Figures.
\end{abstract}

Ke yw $\boldsymbol{w}$ r $\boldsymbol{d}$ s: arc welding, surfacing, pulse algorithms, feed system, electrode wire, welded joint, microstructure

Mechanized and automatic methods of arc welding and surfacing, including in shielding gases, have gained wide acceptance and being continuously improved. Many of published works represent sufficiently important results on indicated processes, but frequently these are not finished researches.

Some delay in investigations of process efficiency of consumable electrode welding and surfacing using wire feed pulse mode system and arc movements along process line was earlier related with their technical imperfection. Currently a series of developments were carried out in this field employing current computerized electric drives based on AC electric motor of special design. In particular, it allowed realizing virtually any algorithm of electrode wire movement, including reverse motion with regulation of all constituents, namely frequency, pitch, pulse amplitude as well as relative pulse duration. At that, frequency range exceeding $50 \mathrm{~Hz}$ is achieved. Expanded process characteristics of new electrode wire feed systems provided the possibility for significant advance in control of geometry characteristics of welded joint, optimizing power consumption and loss of electrode metal.

Results received in works [1-3] allows stating that pulse functioning algorithms of the electrode wire feed systems can be one of the most efficient methods of improvement of mechanized and automatic methods of consumable electrode arc welding and surfacing.
It should be noted that research work on use of current regulated pulse feed systems is carried out with solution of very important problem, i.e. control (in that or another level) of weld metal structure. Importance and ways for solution of mentioned problem are indicated in series of works, for example $[4,5]$, however, as far as we know, at present time no system researches in considered direction using current methods of metallographic investigations are done.

Aim of the present work is a statement of results of carried investigations on process stability, transfer of alloying elements in deposited metal, wear resistance of beads, microstructure of welded joint employing undisturbed and pulse electrode wire feed for process of automatic $\mathrm{CO}_{2}$ surfacing with description and interpretation of obtained results applicable to indices of deposited bead service characteristics.

Figure 1 represents a unit for surfacing of standard plates. Comparative evaluation of stability of process of $\mathrm{CO}_{2}$ arc surfacing at continuous (CFEW) and pulse feed of electric wire (PFEW) were carried out by statistical analysis of recorded oscillograms of welding current and voltage on known procedures [6, 7]. Modes of bead deposition at CFEW and PFEW are the following: $I \approx 230-250 \mathrm{~A}, U=27 \mathrm{~V}$ and average rate of electrode wire feed $v_{\text {av.w.f }}=0.1 \mathrm{~m} / \mathrm{s}$. PFEW frequency made $25 \mathrm{~Hz}$, relative pulse duration was 3 units.

Analysis of values of such statistical parameters, as dispersion, mean-square deviation and coefficients 
Table 1. Parameters of surfacing process stability at CFEW and PFEW

\begin{tabular}{|c|c|c|c|c|}
\hline \multirow{2}{*}{ Stability parameter } & \multicolumn{5}{|c|}{ Surfacing modes } \\
\cline { 2 - 5 } & $I_{\mathrm{a}}$ & $U_{\mathrm{a}}$ & $t_{\mathrm{a}}$ & $t_{\text {sh.c }}$ \\
\hline \multicolumn{5}{|c|}{ CFEW } \\
\hline $\bar{\chi}_{\mathrm{av}}$ & 230.53 & 29.43 & 0.031 & 0.006 \\
\hline$\sigma^{2}(x)$ & 148.49 & 0.77 & $0.75 \cdot 10^{-4}$ & $0.1 \cdot 10^{-5}$ \\
\hline$\sigma(x)$ & 12.19 & 0.88 & 0.0087 & 0.001 \\
\hline$k_{v}(x)$ & 5.29 & 2.99 & 28.06 & 16.67 \\
\hline \multicolumn{5}{|c|}{ PFEW } \\
\hline $\bar{\chi}_{\text {av }}$ & 175.54 & 30.05 & 0.036 & 0.004 \\
\hline$\sigma^{2}(x)$ & 71.17 & 0.0625 & $0.4 \cdot 10^{-5}$ & $0.17 \cdot 10^{-6}$ \\
\hline$\sigma(x)$ & 8.44 & 0.25 & 0.002 & $0.41 \cdot 10^{-3}$ \\
\hline$k_{v}(x)$ & 4.81 & 0.83 & 5.56 & 10.25 \\
\hline $\bar{\chi}-$ process parameter of surfacing. \\
\hline
\end{tabular}

of current variation $I_{\mathrm{a}}$ and voltage $U_{\mathrm{a}}$ in a region of droplet growth, duration of this region $t_{\mathrm{a}}$ and time of short circuit $t_{\text {sh.c }}$ (Table 1) shows that at PFEW there is a reduction of the coefficients of voltage variation in region of droplet growth and 3.5 and 5 times decrease of duration of this region, respectively. It is known fact [6-8] that spattering of electrode metal and quality of deposited bead formation are tightly related with the indices of stability of burning of reverse polarity arc in consumable electrode. Therefore, significant increase of stability of surfacing process under effect of inertia, applied to electrode wire edge, can be an explanation of dramatic decrease of the value of electrode metal loss at PFEW [1-4]. The result of complex investigations on evaluation of effect of PFEW parameters on geometry of deposited metal and loss of electrode metal allowed determining a range of pulse frequency change for $1.2 \mathrm{~mm}$ electrode wire, which is mostly suitable for surfacing tasks (on criteria of minimum portion of the base metal), namely frequency $f=10-30 \mathrm{~Hz}$ and relative pulse duration $S=3-5$ units.

Regardless the fact that volume of droplet of electrode metal and duration of its growth at PFEW are somewhat increased in comparison with CFEW (Figure 2, see Table 1), there are not conditions for

Table 2. Comparative results of emission spectral analysis of deposited metal of 30KhGSA type at CFEW and PFEW of $1.2 \mathrm{~mm}$ diameter in $\mathrm{CO}_{2}$ surfacing

\begin{tabular}{|l|c|c|c|c|c|}
\hline \multirow{2}{*}{ Specimen } & \multicolumn{5}{|c|}{ Content of elements, wt.\% } \\
\cline { 2 - 6 } & $\mathrm{C}$ & $\mathrm{Si}$ & $\mathrm{Mn}$ & $\mathrm{Cr}$ & $\mathrm{Ni}$ \\
\hline 1 layer (CFEW) & 0.17 & 0.87 & 1.10 & 0.63 & $<0.10$ \\
\hline 1 layer (PFEW) & 0.17 & 0.80 & 1.06 & 0.55 & $<0.10$ \\
\hline 5 layer (CFEW) & 0.20 & 0.70 & 0.84 & 0.90 & $<0.10$ \\
\hline 5 layer (PFEW) & 0.21 & 0.78 & 0.81 & 0.98 & $<0.10$ \\
\hline $\begin{array}{l}\text { Note. Surfacing was carried out on 09G2S steel plate (GOST } \\
\text { 19281-89) using Np-30KhGSA wire (GOST 10534-98); data were } \\
\text { taken from polished area of longitudinal bead surface (unit DFS-36). }\end{array}$
\end{tabular}

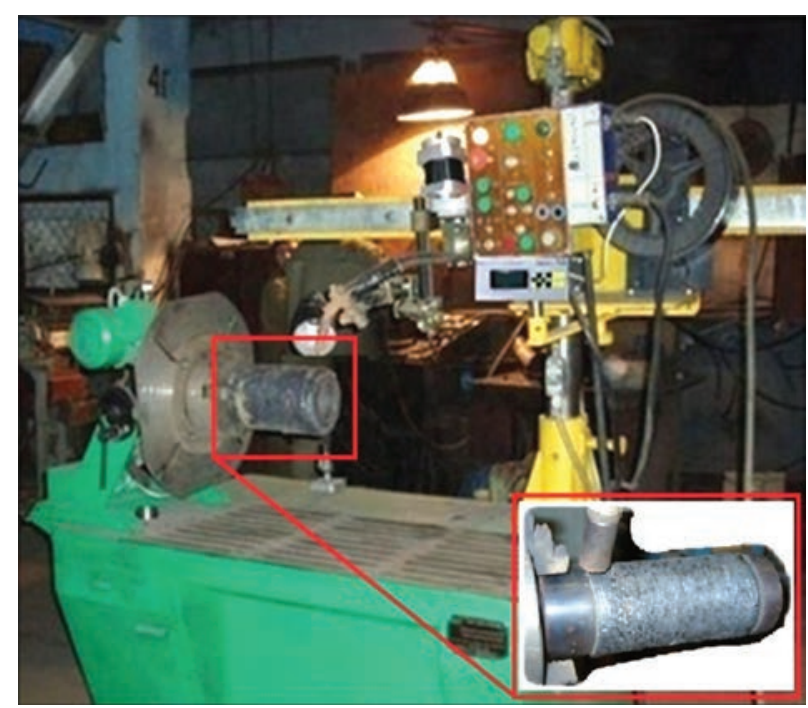

Figure 1. IZRM-5 unit with PFEW mechanism

significant reduction of transfer of alloying elements in the deposited metal (Table 2). Calculated estimation of droplet temperature using its total heat, based on data of high-speed filming and oscillograms of welding current and voltage, showed its reduction by approximately $25 \%$ at $f=10-25 \mathrm{~Hz}$ and $S=3-5$ for PFEW.

Investigations of effect of parameters of PFEW on service properties of the deposited layer showed (Figure 3 ) that this method, applying $f=15-20 \mathrm{~Hz}$ and $S=3-5$, allows acquiring wear resistance properties, similar to five-layer surfacing with CFEW, already in the first layer of the deposited metal. Comparison of wear resistance of five-layer deposited metal showed that PFEW also promotes for 1.2-1.4 times improvement of wear resistance (see Figure 3).

Increase of wear resistance characteristics of 30KhGSA deposited metal is provoked, first of all, by significant decrease of base metal penetration depth and, respectively, reduction of its portion in the deposited bead. This effect mainly appears due to $20-30 \%$ limitation of heat amount being emmited at PFEW (Figure 4). This, in turn, based on comparative analysis of oscillograms at CFEW and PFEW, in the latter case is caused by drop of welding current value in the

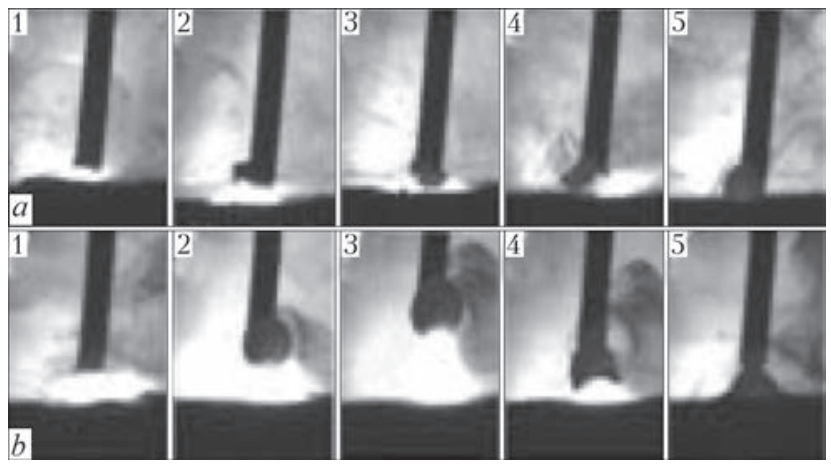

Figure 2. Shots of high-speed filming of electrode metal transfer cycle in $\mathrm{CO}_{2}$ surfacing: $a-\mathrm{CFEW} ; b-\mathrm{PFEW}$ 


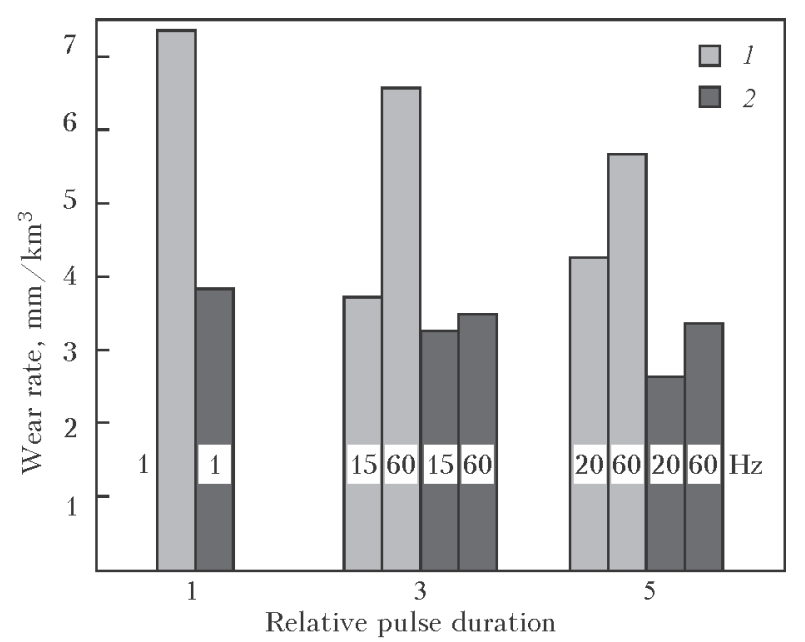

Figure 3. Histogram of evaluation of wear rate of specimens of 30KhGSA deposited metal in wiping of craters using shaft-plane scheme without additional lubrication in friction zone depending on frequency, relative pulse duration and amount of deposited layers $n=1(1)$ and 5 (2) at $I_{\mathrm{av}}=220 \mathrm{~A}$ and $U=26 \mathrm{~V}$

stage of droplet growth due to periodic elongation of arc and reduction of its pressure force on molten weld pool metal.

Comparative experimental investigations of a base-deposited metal welded joint were carried out in order to explain the reasons of increase of wear resistance of 30KhGSA deposited metal at multi-layer surfacing, when effect of mixing of base and deposited metal is virtually eliminated. The microstructure of deposited metal and HAZ in the base metal was examined using optical $\times(50-500)$ and back-scattered SEM methods $\times(500-2000)$ on microsections of single-layer deposits etched in $4 \%$ solution of $\mathrm{HNO}_{3}$. View of observed phases, formed as a result of decomposition of primary austenite grain (ferrite, bainite, pearlite), was specified by means of Vickers's hardness measurement using LECO M400 hardness gauge at $100 \mathrm{~g}$ loading.

It is determined that structure of $30 \mathrm{KhGSA}$ deposits consists of acicular ferrite crystal grains $[9,10]$ (HV0.1-2360-2540 MPa), divided by ferrite layers of up to $2.5 \mu \mathrm{m}$ thickness (Figure 5). Comparative anal-

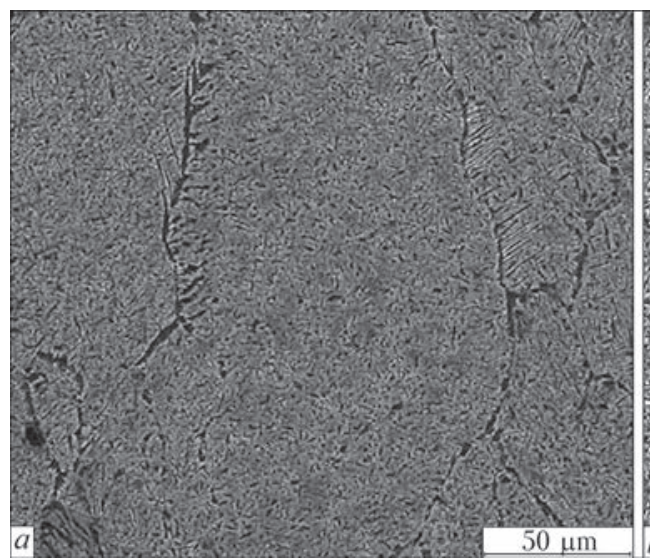

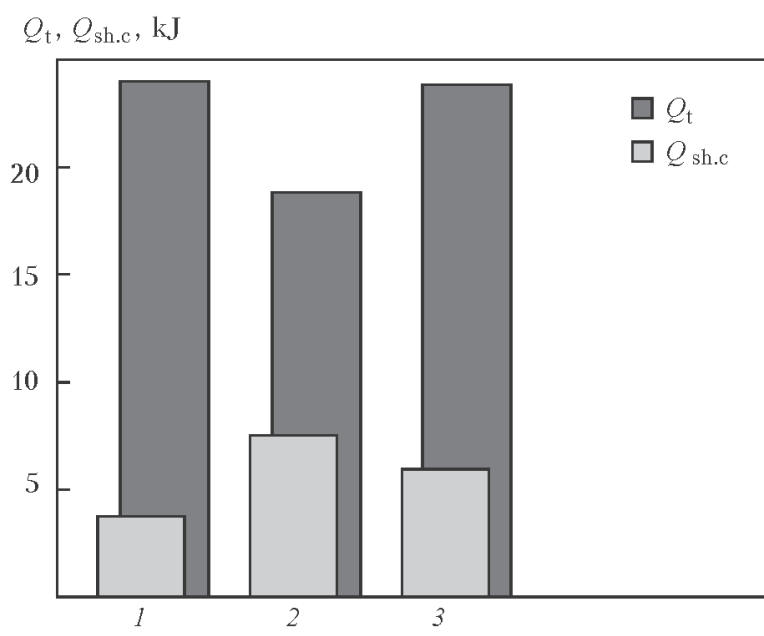

Figure 4. Histogram of evaluation of total heat power $Q_{\mathrm{t}}$ and power in short circuit area $Q_{\text {sh.c }}$ (portion of $Q_{\mathrm{t}}$ ) at CFEW and PFEW during $5 \mathrm{~s}: 1-\mathrm{CFEW} ; 2-\mathrm{PFEW}$ at $25 \mathrm{~Hz} ; 3-\mathrm{PFEW}$ at $60 \mathrm{~Hz}$

ysis of shape and size of crystal grains in the central part of the deposited metal showed that at PFEW they have somewhat smaller width and shape coefficient. Thus, in $\mathrm{CO}_{2}$ surfacing the width of crystal grains at CFEW equals 97.5 and at PFEW it is $70 \mu \mathrm{m}$; coefficient of shape of crystal grains at CFEW equals 6.8 and it makes 4.56 at PFEW. PFEW also promotes a tendency to limitation of length of crystal grains, significant part of which does not exceed $210 \mu \mathrm{m}$ versus 640-700 $\mu \mathrm{m}$ at CFEW.

Metallographic analysis of the deposited metal at larger magnification $\times(1000-2000)$ showed that crystal grain boundary of more favorable shape (Figure 6) is observed at PFEW. In other words, thickness of layers of polygonal ferrite $[9,10]$, which is supposed to be the most dangerous structure from point of view of brittle fracture $[11,12]$, is mainly reduced in $1.5-2$ times; lamellar (Widmanstatten) ferrite $[9,10]$ is absent on crystal grains periphery; precipitation of microparticles of acicular ferrite changes their shape mainly for polyhedrous.

It is known that the structure of acicular ferrite in the weld metal provides for optimum combination of

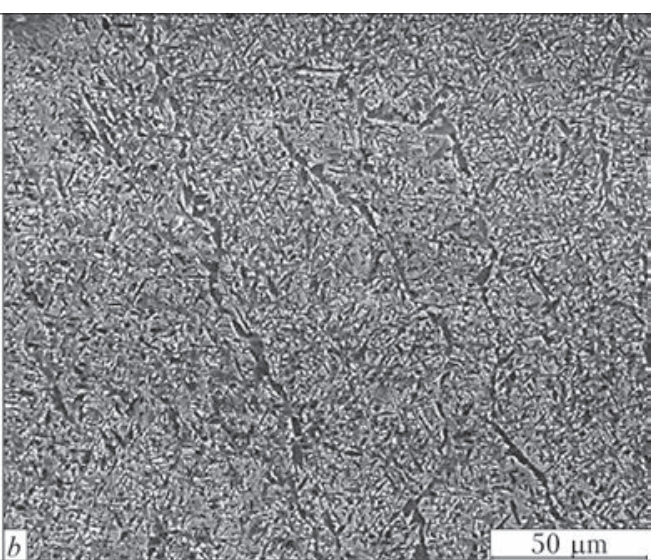

Figure 5. Microstructure of deposited metal of 30KhGSA type: $a-$ CFEW; $b-$ PFEW 

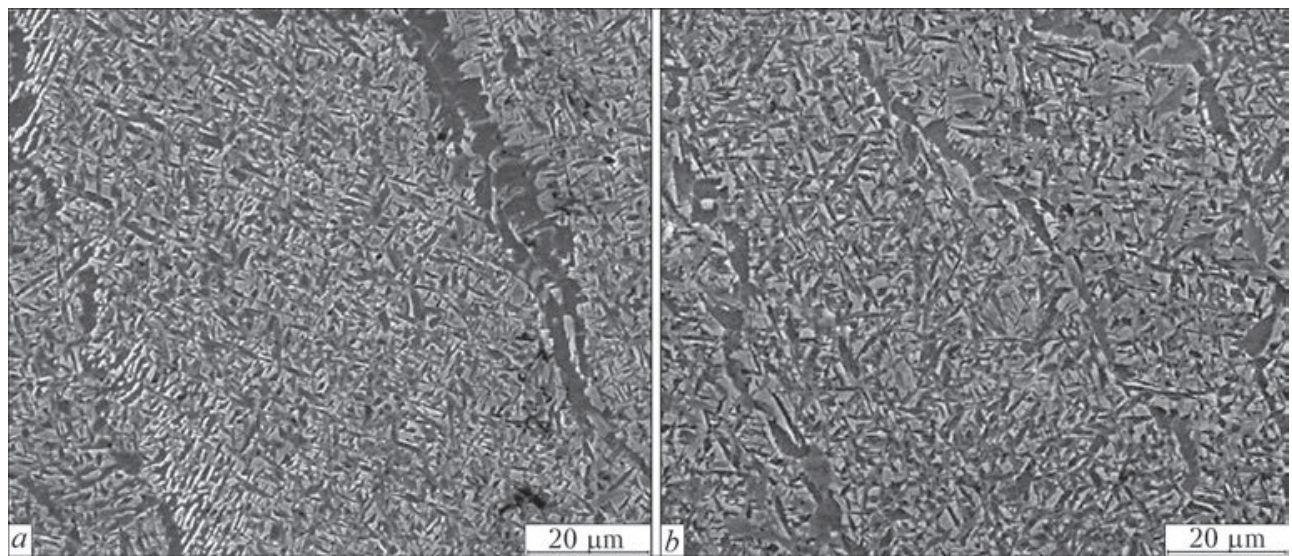

Figure 6. Microstructure of deposited metal of 30KhGSA type: $a-\mathrm{CFEW} ; b-\mathrm{PFEW}$

characteristics of its strength and ductility [11-13] as well as, together with acicular troostite [14], differs by increased wear-resistance in comparison with ferrite-pearlite one (Figure 7). The latter fact is caused by refining the structure of microprecipitates of acicular ferrite to approximately $0.5 \mu \mathrm{m}$ size under the effect of subsurface cold work [15]. The effect of increased wear resistance of acicular ferrite can also be related with presence in it of MAC-microcomplexes (MAC-phase [9, 16, 17]) (Figure 8), distributed inside the crystal grains and along polygonal ferrite layers.

Thus, 20-40\% improvement of wear resistance at five-layer surfacing with PFEW in comparison with CFEW (see Figure 3), under conditions of almost complete elimination of factor of mixing of the base and deposited metals, can be explained by enhancement of acicular ferrite structure, namely more favorable shape of crystal grains, reduction of volume fraction of polygonal and lamellar ferrite on their periphery, and, probably, optimization of morphology and distribution of MAC-phase in acicular ferrite content.

At CFEW the crystal grains of $20-40 \mu \mathrm{m}$ width with ferrite fringes of 2.0-2.5 $\mu \mathrm{m}$ (Figure 9, $a$ ) are present in the deposited metal close to fusion line. It means significant increase of volume fraction of the fringes of polygonal and lamellar ferrite (HVO.12210-2280 MPa) on the periphery of crystal grains. Such a structure, based on data of work [13], promotes

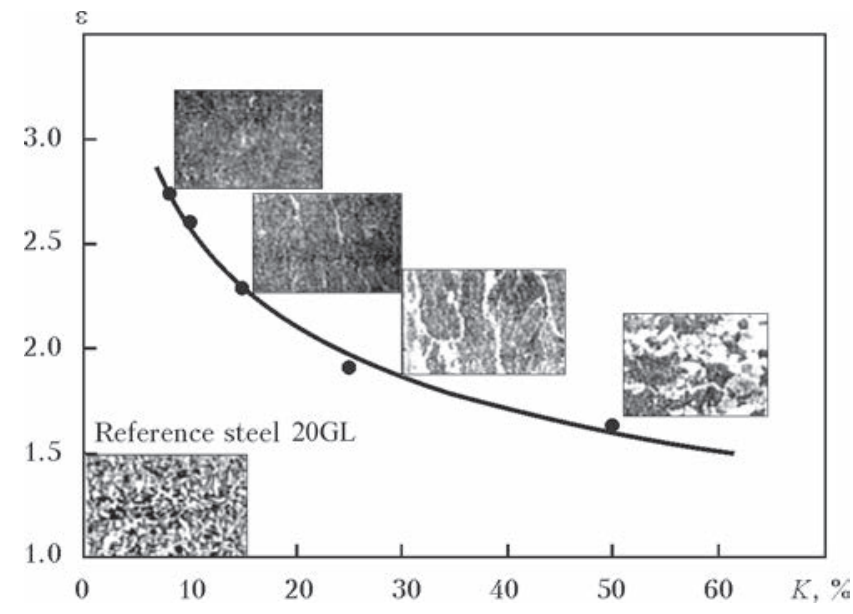

Figure 7. Relative wear resistance of deposited metal $\varepsilon$ versus volume fraction of polygonal ferrite $K$ [15]

for increase of weld susceptibility to brittle fracture. Presence of disoriented structure virtually without polygonal ferrite fringes (Figure 9, $b$ ) is observed at PFEW in the deposited metal close to fusion line.

The next structural constituents are observed (Figure 10) in HAZ in 09G2S base metal: lower bainite (HV0.1-3000-3500), upper bainite (HV0.1-26002660) and lamellar ferrite (HV0.1-2210-2280 MPa). More uniform microstructure, consisting of upper and lower bainite with somewhat reduced content of lamellar ferrite (Figure 10, $b$ ) is present at PFEW in HAZ metal in the coarse grain region. Also a tendency
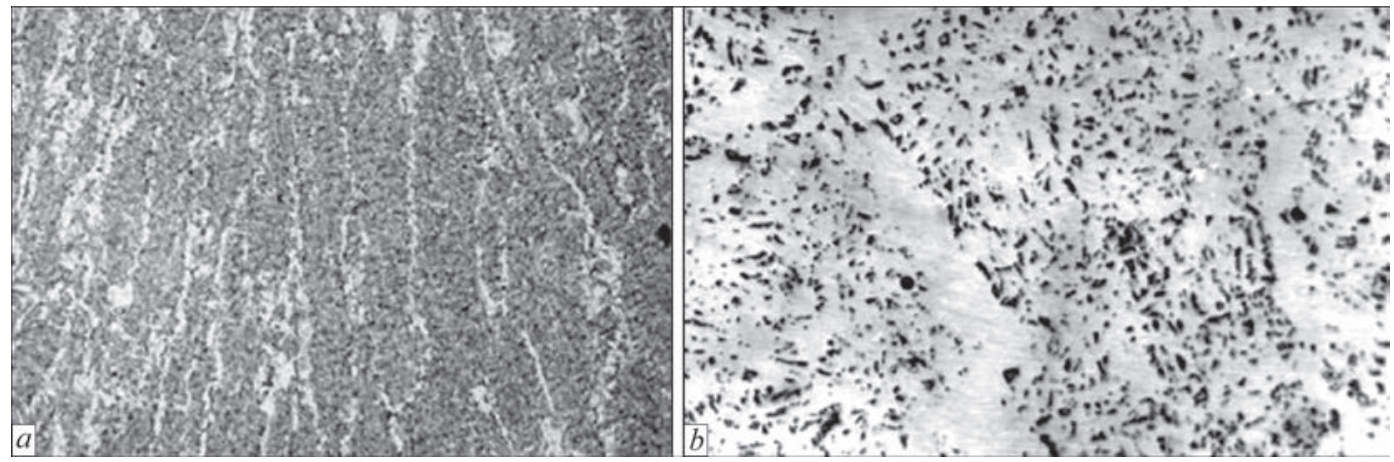

Figure 8. Microstructure of weld metal in 10G2FB steel obtained with Mn-Ni-Mo wire and flux AN60: $a-$ etching in nital $(\times 100)$; $b$ - in sodium picrate $(\times 800)[13]$ 


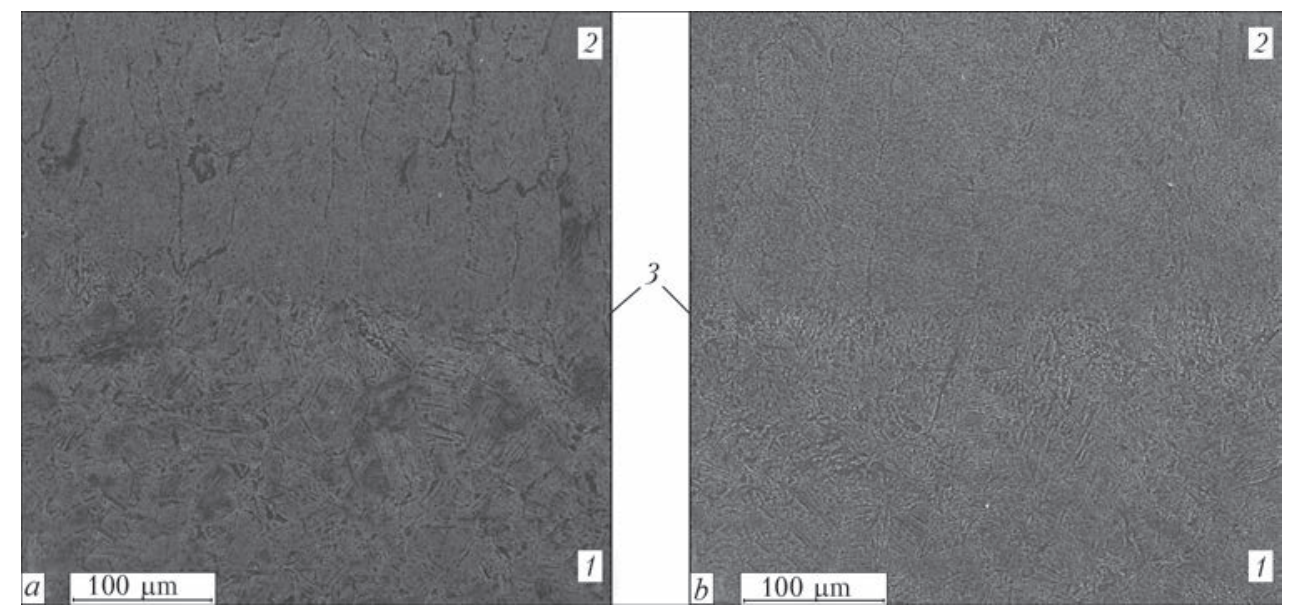

Figure 9. Microstructure in area of fusion line at CFEW $(a)$ and PFEW $(b): 1-09 \mathrm{G} 2 \mathrm{~S}$ base metal; 2 - 30KhGSA deposited metal; 3 - fusion line

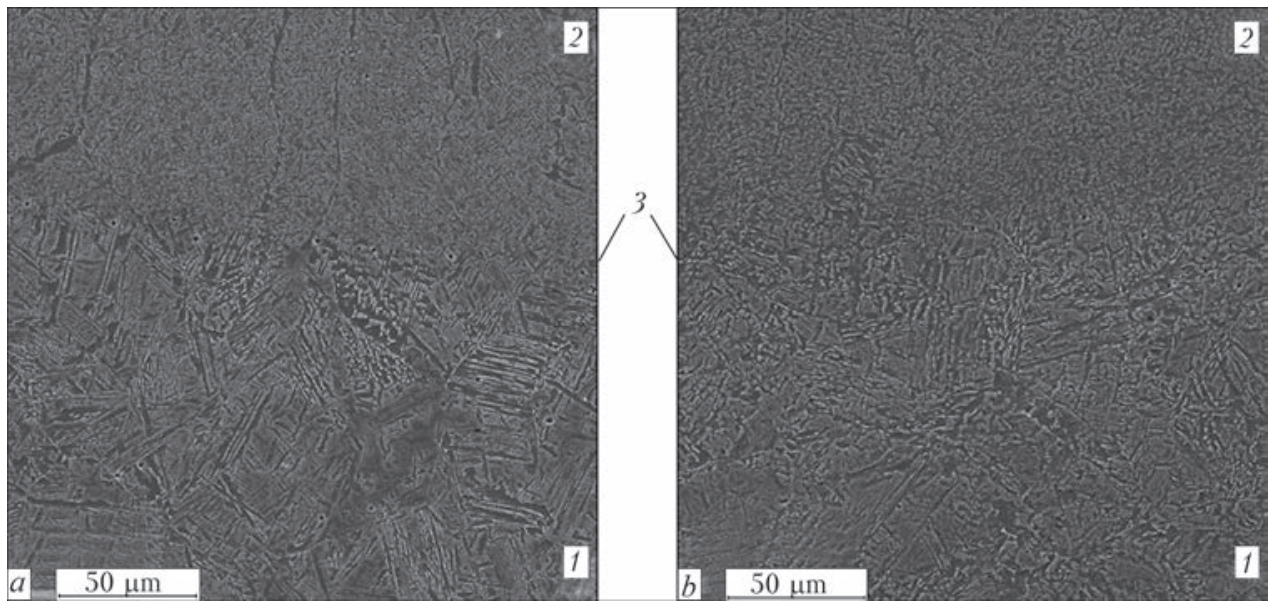

Figure 10. Microstructure in area of fusion line at CFEW (a) and PFEW (b): 1 -09G2S base metal; 2 -30KhGSA deposited metal; 3 - fusion line

to transfer of upper and lower bainite microstructure from acicular to grain morphology (see Figure 10,b) is noted in HAZ metal at PFEW. Based on data of work [18], such a structure is the most favorable from point of view of weldability of the base metal and service reliability of its HAZ, in particular, under conditions of low temperatures.

There is a significant drop of microhardness in fine grain region of $\mathrm{HAZ}$ of $09 \mathrm{G} 2 \mathrm{~S}$ base metal. It made HV0.1-2160-2280 at CFEW and HV0.1-2060 $2130 \mathrm{MPa}$ at PFEW. Ferrite regions were present in incomplete solidification area, and microhardness, respectively, approached to the values typical for base metal: HV0.1-1700-1810 at CFEW and HV0.1-1870 $2060 \mathrm{MPa}$ at PFEW. Banded ferrite-pearlite structure was present in the depth of 09G2S base metal; its microhardness made HV0.1-1470-1600 MPa.

\section{Conclusions}

1. It is shown that process of $\mathrm{CO}_{2}$ arc surfacing with PFEW is characterized by increased stability and smaller loss of electrode metal for spattering in comparison with CFEW.

2. Optimum range of PFEW parameters is determined, namely $f=10-30 \mathrm{~Hz}$ and $S=3-5$. It is shown that limitation of penetration depth is achieved due to current reduction at stage of droplet growth in elementary cycle of electrode metal transfer, and, respectively, heat inputs, common for this cycle.

3. It is determined that $30 \mathrm{KhGSA}$ metal deposited in optimum range of PFEW parameters has increased wear resistance in comparison with CFEW. This effect is reached due to reduction of portion of base metal in the deposited one and microlevel improvement of structure in the body and on the boundary of acicular ferrite crystal grains (magnification more than $\times 500$ ).

4. It is shown that at PFEW the microstructure of deposited metal in area of fusion line and HAZ of the base metal is the most favorable from point of view of weldability and service reliability of the welded joint.

1. Lobanov, L.M., Lebedev, V.A., Maksimov, S.Yu. et al. (2012) New capabilities of mechanized arc spot welding using pulse effects. The Paton Welding J., 5, 12-16. 
2. Lebedev, V.A., Lendel, I.V. (2013) Control of pulse movement of electrode wire in mechanized welding due to change of feed pitch. Zagotovit. Proizv. v Mashinostroenii, 3, 10-14.

3. Paton, B.E., Lebedev, V.A., Poloskov, S.I. et al. (2013) Application of mechanical pulses for control of processes of automatic and mechanized consumable electrode welding. Svarka i Diagnostika, 6, 16-20.

4. Lebedev, V.A., Lendel, I.V. (2015) Investigation of technological possibilities of arc welding and surfacing with pulsed feed of electrode wire. Nauk. Tekhn. v Mashinostroenii, 9 , $20-27$.

5. Lebedev, V.A. (2007) Specifics of welding of steels with pulsed feed of electrode wire. Svarochn. Proizvodstvo, 8, 30-35.

6. (1990) Metallurgy of arc welding. Processes in arc and melting of electrodes. Ed. by I.K. Pokhodnya. Kiev: Naukova Dumka.

7. Lankin, Yu.N. (2011) Indicators of stability of GMAW process. The Paton Welding J., 1, 6-13.

8. Potapievsky, A.G., Saraev, Yu.N., Chinakhov, D.A. (2012) Gas metal arc welding of steels. Engineering and technology of future. Tomsk: TomskPU.

9. Abson, D.I., Dolby, R.E., Hart, P.M. (1978) The role of nonmetallic inclusions in ferrite nucleation in carbon steel weld metals. In: Trends in steel and consumables for welding: TWI Conf. Proc. London: TWI.
10. Hee Jin Kim, Bong Yong Kang (2000) Microstructural characteristics of steel weld metal. J. KWS, 18(5), 565-572.

11. Curry, D.C., Knott, J.F. (1978) Effects of microstructure on cleavage fracture stress in steel. Metal Sci., Vol. 12, 511.

12. Kostin, V.A. (2008) Complex assessment of manganese and titanium effect on structure and properties of low-alloy steel welds. Visnyk PryazovDTU, 18, 198-202.

13. Rybakov, A.A., Kostin, V.A., Filipchuk, T.N. et al. (2013) Peculiarities of microstructure formation of weld metal of gas-and-oil pipelines in welding of micro-alloy steels. Visnyk ChernigDTU, 63(1), 125-131.

14. Frumin, I.I. (1961) Automatic electric arc surfacing. Kharkov: Metallurgizdat.

15. Abramenko, D.N. (2008) Improvement of wear resistance of freight car parts by arc surfacing of steel layer with acicular ferrite structure: Syn. of Thesis for Cand. of Techn. Sci. Degree. Moscow: TsNIITMASh.

16. Yurioka, N. (1995) TMPC steel and their welding. Welding in the World, 35(6), 375-390.

17. Hrivnak, I., Matsuda, F. (1994) Metallographic examinations of martensite-austenite component (MAC) of HAZ metal of high-strength low-alloy steels. Avtomatich. Svarka, 3, 22-30.

18. Ivanajsky, A.A. (2006) Analysis of structure, phase composition, properties of granular bainite and technology of its formation in welded joints and rolled metal for welded structures: Syn. of Thesis for Cand. of Techn. Sci. Degree. Barnaul: AltajGTU. 